\title{
Endovascular Treatment of Focal Infrarenal Aortic Stenosis with Absence of the Celiac Trunk - Case Report
}

\section{Abstract}

Purpose: This case report describes a case of abdominal aortic stenotic disease treated with covered balloon- expandable stent with absence of the celiac trunk artery.

Technique: Patients are selected for this strategy if they have a lesion without bifurcation involvement located at the mid segment of the infrarenal aorta or stenosis with unfavorable aortic anatomy, or severely diseased and calcified distal aorta.

Conclusion: Our result in this case supports the feasibility, safety, and efficacy of stenting for stenosis of the distal infrarenal aorta.

Keywords: Aortic stenosis; Endovascular procedures; Angioplasty; Endovascular surgery; Celiac trunk variation

Received: February 10, 2016; Accepted: February 27, 2016; Published: March 05, 2016

\section{Introduction}

The early surgical treatments of aortic stenosis were endarterectomy or bypass surgery and have been used exclusively until the 1980s [1]. The surgical approach was considered as the standard treatment for occlusive disease of the abdominal aorta in chronic arterial stenosis or occlusions with great calcium component. Percutaneous transluminal angioplasty (PTA) has been proposed as an alternative to surgery, and several series have demonstrated its safety and efficacy in localized stenosis of the distal infra renal aorta $[2,3]$. The feasibility of a randomized study comparing endovascular treatment to open surgery is low because of the rarity of the disease, however, more data could help to perform meta-analyses. Short aortic occlusions are not a risk factor for the early and late patency rate and should be downgraded from group TASC D and could be first line approach for infrarenal aortic occlusive disease [4]. Few minor series have been published and no agreement has been found regarding which procedure should be considered as a first line treatment $[5,6]$.

The incidence of focal distal aortic stenosis without involvement of the aortic bifurcation is quite low so these lesions are usually reported in the literature along with stenosis involving the aortoiliac junction [7-10]. The incidence of isolated stenosis in the
Ocke Reis $\mathrm{PE}^{1,3}$,

Roever $\mathrm{L}^{2}$, Fontes $\mathrm{FA}^{3}$,

Nascimento $\mathrm{MR}^{3}$,

Sandri PA ${ }^{1,3}$, Ocke Reis IF ${ }^{3}$, Maia VN ${ }^{1,3}$, Rajo VLP ${ }^{1,3}$, Araujo $\mathrm{DA}^{1,3}$ and Oroski $\mathrm{MM}^{1,3}$

1 Department of Specialized and General Surgery, Fluminense Federal University (UFF), Niterói, Rio de Janeiro, Brazil

2 Federal University of Uberlândia, Department of Clinical Research, Brazil

3 Vascular Clinic Ocke Reis, Rio de Janeiro, Brazil

Corresponding author:

Paulo Eduardo Ocke Reis

”v vascular@pauloocke.com.br

Rua Visconde de Pirajá 414/1117, Ipanema, CEP 22410-002, Rio de Janeiro, Brazil.

Tel: $212287-5327$

Citation: Ocke Reis PE, Roever L, Fontes FA, et al. Endovascular Treatment of Focal Infrarenal Aortic Stenosis with Absence of the Celiac Trunk - Case Report Journal of Vascular \& Endo Surgery. 2016, 1:1.

infrarenal aorta appears to be higher in young women, perhaps attributable to nicotine abuse $[7,11,12]$

\section{Case Report}

A 64-year-old woman, smoker, hypertensive, booked electively from an out- patient clinic with bilateral rest pain and her physical exam showed no palpable femoral pulses. She was evaluated pre-procedure with Computed Tomography (CT) angiogram, that revealed a mid-infrarenal aortic stenosis and the aortic diameter was measured on CT sections (Figure 1) with an ana tomic variation with the absence of the celiac trunk and output of direct branches of the aorta (Figure 2). Aorta with parietal calcifications in the infra renal segment with calcified plaques that promote reduction of the arterial lumen by $75 \%$. Color doppler ultrasonography: "Flow with VPS $>400 \mathrm{~cm} / \mathrm{s}$ with an estimated aortic obstruction to be $>75 \%$ with distal single-phase flow. The procedure was performed under general anesthesia and a 


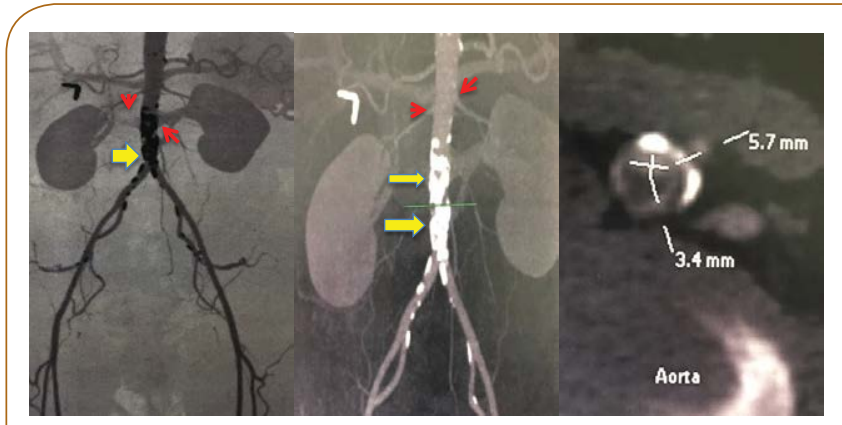

Figure 1 Respectively from left to right - A mid-infrarenal aortic stenosis(yellow arrows), renal arteries (red arrows) and the aortic diameter was measured on CT sections showing the focal critical aortic stenosis and absence of the celiac trunk artery.

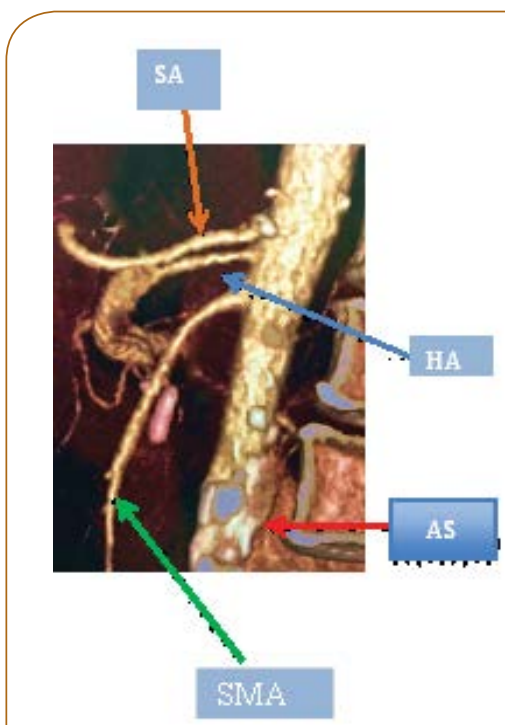

Figure 2 Three-dimensional reconstruction of the computerized tomographic angiography demonstrated infrarenal aortic stenosis (AS- red arrow), absence of the celiac trunk artery, patent hepatic artery (HA- blue arrow) and splenic artery(SA - orange arrow) with direct branches of the aorta and proximal superior mesenteric (SMA green arrow).

unilateral right femoral approach was used. An introducer sheath with appropriate diameter (7F) matching the size of the intended stent was placed at the ipsilateral common femoral artery, and a bolus of heparin (5000 IU) was given intravenously. An initial angiography was then performed with a $5 \mathrm{Fr}$ sheath inserted and following guide wire access; a digital subtraction angiogram was performed via a pigtail catheter (Figure 3). Followed by direct aortic progressive ballon angioplasty sizes 5, $7 \times 40 \mathrm{~cm}$ Power Flex Pro (Figure 3). A covered ballon-expandable endoprosthesis, Atrium Advanta V $1210 \times 38 \mathrm{MM}$ (Atrium Australia-Pacific Rim Pty LTD, NSW) it was properly placed and covers the entire lesion. At the end of the procedure, a completion angiogram was performed for demonstration of the final result and radiological success (Figures $\mathbf{3}$ and 4). Physical examination in the immediate postoperative showed femoral, popliteal and posterior tibial pulse in both limbs, as they were absent at the preoperative

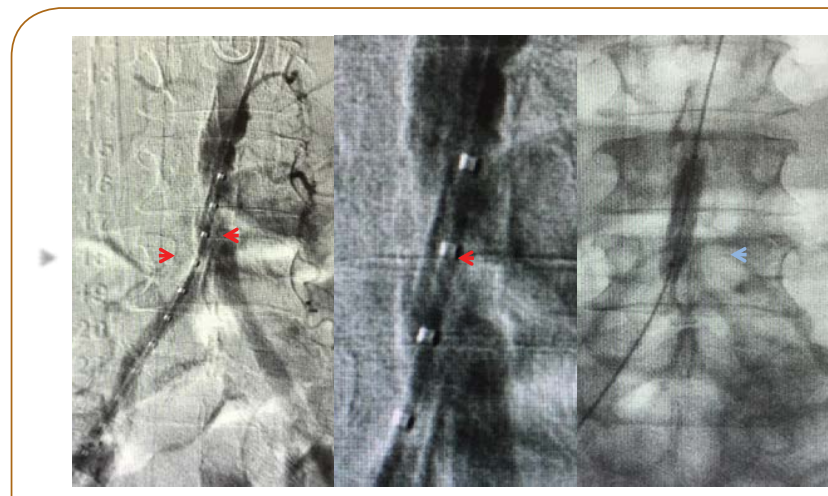

Figure 3 Angiography demonstrated respectively from left to right, first a large calcified aortic lesion (red arrows), at the level of the mid-infrarenal abdominal aortic. The focal lesion in detail and the ballon angioplasty (blue arrow) before treating with covered balloonexpandable stent.

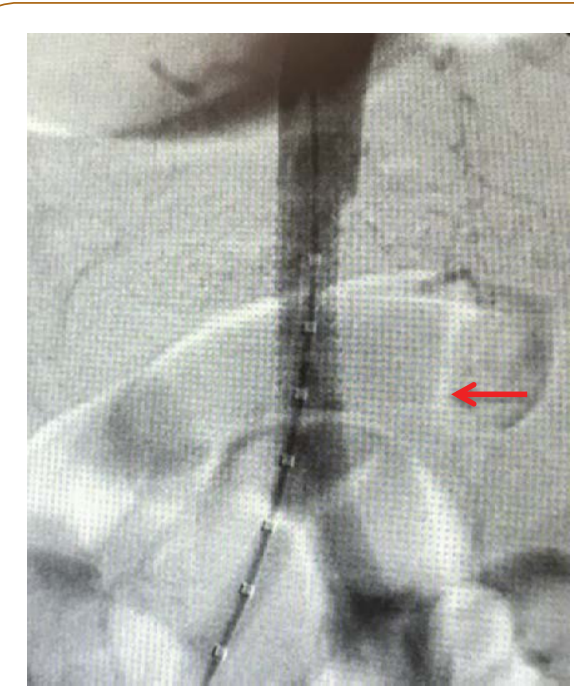

Figure 4 Angiography demonstrated a covered ballonexpandable endoprosthesis, Atrium advanta V 12 $10 \times 38 \mathrm{MM}$ appropriately placed in the mid-infrarenal abdominal aortic (red arrow), demonstrating the final result and radiological success.

examination. The patient had an uneventful recovery in the immediate postoperative period and discharged 24 hours after the procedure for follow-up at the outpatient clinic using AAS $100 \mathrm{mg}$ and simvastatin $40 \mathrm{mg}$.The trunk celiac absence does not interfere in technical details during or results of the procedure, however all surgeons must study anatomy of the abdominal viscera in planning and conducting surgical or interventional procedures of each patient.

\section{Discussion}

We report our case with aortic stent alone to treat stenosis, TASC B (Lesion was classified according to severity using the TASC II guidelines), with covered balloon-expandable stent [5]. This case demonstrates that treatment of complex aortoiliac occlusive disease with covered balloon- expandable stents can have 
acceptable results with good clinical outcome [13]. Secondary patency rates are comparable to open surgical revascularization, with lower morbidity [13]. The Trans-Atlantic Inter-Society Consensus (TASC) II guidelines for treatment of aorto-iliac occlusive disease recommend an endovascular approach for patients with focal or short lesions, namely TASC A or B $[5,13]$ Studies have shown technical success rates of 95 to $100 \%$ for angioplasty of the infra-renal aorta and angioplasty of the aortic bifurcation $[2,6,14]$. Stenting the aorta yields similar success rates of 87 to $100 \%$, with a primary patency of 80 to $100 \%$ at 3 to 10 years $[15,16]$. Whether stenting increases patency rates over balloon angioplasty alone remains unclear. Rutger et al. have shown that the use of PTFE (Polytetrafluoroethylene) - covered stents for isolated atherosclerotic lesions in the infrarenal aorta is safe, feasible, and associated with an excellent outcome [17]. During follow-up, all stents remained patent, which indicates that covered stents may be a valid alternative for surgery [17]. It must be noted, however, that isolated aortic disease is likely to be different from bifurcation and isolated iliac disease from a hemodynamic standpoint. Those results on focal aortic lesions are limited by the small sample size and study design[17]. Longer follow up periods, are required to confirm acceptable longterm patency rates compared with open surgical intervention in patients with radiological severe disease [13]. Comparative studies with traditional treatment modalities are indicated to assess the role of covered stents in the treatment strategy of these lesions $[13,17]$. Covered stents may reduce re stenosis caused by intimal hyperplasia [18]. Tewksbury et al. follow-up revealed four cases of re- stenosis, with three successful re-interventions for a secondary patency rate of $97 \%$ [13]. This is in keeping with the results of the COBEST trial, which reported a secondary patency of $95 \%$ at 12 months for TASC C and D treated lesions $[13,18]$

Agenesis of the celiac axis has only been reported a few times and is also extremely rare [19-23]. The more common congenital anomaly of a combined celio-mesenteric trunk is estimated to occur in $1 \%$ of individuals $[19,24]$.

\section{Conclusion}

Our result in this case supports the feasibility, safety, and efficacy of primary stenting for stenosis of the distal infrarenal aorta with absence of the celiac trunk. Although larger prospective randomized studies with long-term follow-up are necessary to compare surgery, PTA, and primary stent placement. 


\section{References}

1 De Vries SO, Hunink MG (1997) Results of aortic bifurcation grafts for aortoiliac occlusive disease: a meta-analysis. J Vasc Surg 26: 558-569.

2 2.Heeney D, Bookstein J, Daniels E, Warmath M, Horn J, et al. (1983) Transluminal angioplasty of the abdominal aorta. Radiology 148: 8183.

3 Sheeran SR, Hallisey MJ, Ferguson D (1997) Percutaneous transluminal stent placement in the abdominal aorta. J Vasc Interv Radiol 8: 55-60.

4 Schwindt AG, Panuccio G, Donas KP, Ferretto L, Austermann M, et al. (2011) Endovascular treatment as first line approach for infrarenal aortic occlusive disease. J Vasc Surg 53: 1550-1556.

5 Norgren L, Hiatt WR, Dormandy JA, Nehler MR, Harris KA, et al. (2007) Inter-society Consensus for the Management of Peripheral Arterial Disease (TASC II). Eur J Vasc Endovasc Surg 1: S1-S75.

6 Klonaris C, Katsargyris A, Tsekouras N, Alexandrou A, Giannopoulos A, et al. (2008) Primary stenting for aortic lesions: from single stenoses to total aortoiliac occlusions. J Vasc Surg 47: 310-317.

7 Ruppert V, Wirth S, Rieger J, Kueffer G, Steckmeier B, et al. (2006) Long-term Results After Primary Stenting of Distal Aortic Stenosis. J Endovasc Ther 13: 229-236.

8 Audet P, Therasse E, Oliva VL, Soulez G, Côté G, et al. (1998) Infrarenal aortic stenosis: long-term clinical and hemodynamic results of percutaneous transluminal angioplasty. Radiology 209: 357-363.

9 9.d'Othee BJ, Haulon S, Mounier-Vehier C, Beregi JP, Jabourek O, et al. (2002) Percutaneous endovascular treatment for stenoses and occlusions of infrarenal aorta and aortoiliac bifurcation: midterm results. Eur J Vasc Endovasc Surg 24: 516-523.

10 Schedel H, Wissgott C, Rademaker J, Steinkamp HJ (2004) Primary stent placement for infrarenal aortic stenosis: immediate and midterm results. J Vasc Interv Radiol 15: 353-359.

11 McPherson SJ, Laing AD, Thomson KR, Mitchell PJ, Milne P, et al. (1999) Treatment of infrarenal aortic stenosis by stent placement: a 6-year experience. Australas Ra- diol 43: 185-191.

12 Becker GJ, Katzen BT, Dake MD (1989) Non coronary angioplasty. Radiology 170: 921-940.
13 Tewksbury R, Taumoepeau L, Cartmill A, Butcher A, Cohen T (2015) Outcomes of covered expandable stents for the treatment of TASC D aorto-iliac occlusive lesions. Vascular 23: 630-636.

14 Tadavarthy AK, Sullivan WA, Nicoloff D, Castaneda-Zuniga WR, Hunter DW, et al. (1989) Aorta balloon angioplasty: 9-year follow-up. Radiology 170: 1039-1041.

15 Hallisey MJ, Meranze SG, Parker BC, Rholl KS, Miller WJ, et al. (1994) Percutaneous transluminal angioplasty of the abdominal aorta. J Vasc Interv Radiol 5: 679-687.

16 Nyman U, Uher P, Lindh M, Lindblad B, Ivancev K (2000) Primary stenting in infrarenal aortic occlusive disease. Cardiovasc Intervent Radiol 23: 97-108.

17 Bruijnen CG, Grimme FAB, Horsch AD, Van Oostayen JA, Zeebregts CJ, et al. (2012) Primary balloon expandable polytetrafluoroethylenecovered stenting of focal infrarenal aortic occlusive disease. J Vasc Surg 55: 674-678.

18 Mwipatayi BP, Thomas S, Wong J, Temple SE, Vijayan V, et al. (2011) A comparison of covered vs bare expandable stents for the treatment of aortoiliac occlusive disease. J Vasc Surg 54: 1561-1570.

19 Armstrong PJ, Franklin DP (2006) Superior Mesenteric Artery Branch Aneurysm with Absence of the Celiac Trunk. Vascular 14: 109-112.

20 Maier JP, Patetsios P, Moglia RM, Dietz PA (2002) Superior mesenteric artery aneurysm in a patient with congenital absence of the celiac axis. J Am Coll Surg 195: 279.

21 Partensky C, Descos L, Chapeteier P, Bretagnolle M, Bret PM (1987) Aneurysm of an abnormal pancreatic arch with agenesis of the celiac trunk. Gastroenterol Clin Biol 11: 260.

22 Vogler C, Faiss J, Krause FJ, Schwanborn G (1991) Aneurysm of the gastroduodenal artery with aplasia of the celiac trunk. Chirurg 62 : 503-504.

23 Basar R, Onderogul S, Cumhur T, Yüksel M, Olçer T (1995) Agenesis of the celiac trunk: an angiographic case. Kaibogaku Zasshi 70: 180182.

24 Kalra M, Panneton JM, Hofer JM, Andrews JC (2003) Aneurysm and stenosis of the celiomesenteric trunk: a rare anomaly. J Vasc Surg 37: 679-678 